\title{
Quantifying relationships between environmental factors and power dissipation on the most prolific days in the largest tornado 'outbreaks'
}

\section{Zoe Schroder $^{1 *} \quad$ James B. Elsner ${ }^{1 \dagger}$}

${ }^{1}$ Department of Geography, Florida State University, Florida, 32306, USA

\section{Correspondence}

Zoe Schroder, MS, Department of Geography, Florida State University, Tallahassee, Florida, 32306, USA

Email: zms17b@my.fsu.edu

Funding information

The authors received no funding for this work.
Studies show an increasing tendency for tornadoes in the United States to occur in larger outbreaks. To shed light on the reason for this the authors use a regression model to quantify the relationship between convective environmental variables and accumulated tornado power (ATP). They consider only days with many tornadoes that occur as part of an outbreak. Results show an average upward trend in ATP at 5\% [(2.5\%, 12\%), 95\% uncertainty interval] per year. ATP increases by $125 \%$ for every $10 \mathrm{~m} \mathrm{~s}^{-1}$ increase in bulk shear (on average) holding the other variables constant and by $33 \%$ for every $1000 \mathrm{~J} \mathrm{~kg}^{-1}$ increase in convective available potential energy holding the other variables constant. Changes in bulk shear, which has the largest effect on ATP, might help explain the documented changes in tornado activity.

\section{KEYWORDS}

tornado outbreaks, accumulated tornado power, atmospheric environments, regression model 


\section{INTRODUCTION}

2 Tornadoes pose a significant risk to life and property in the United States. The strongest tornadoes, producing the majority of fatalities, occur in clusters (Elsner et al., 2015; Fuhrmann et al., 2014; Dean and Schneider, 2012; Schneider et al., 2004; Mercer et al., 2009; Galway, 1977). In fact, three-fourths of all fatalities occur on days with at least ten tornadoes. For example, the April 27, 2011 outbreak produced 199 tornadoes that resulted in 316 fatalities and more than 2700 injuries. Insured losses exceeded \$11 billion (Knupp et al., 2014).

Tornado clusters ('outbreaks') occur generally east of the Rocky Mountains and west of the Appalachian Mountains (Dean, 2010) during the months of April, May, and June (Dixon et al., 2014; Tippett et al., 2014, 2012; Trapp, 2014; Dean, 2010; Galway, 1977). Outbreaks are largely confined to the Southeast during the late fall and winter months (Dean, 2010). The percentage of all U.S. tornadoes occurring in clusters is on the rise (Moore, 2017; Tippett et al., 2016; Elsner et al., 2015; Tippett et al., 2014; Brooks et al., 2014; Moore and DeBoer, 2019; Moore, 2018; Fuhrmann et al., 2014). Tippett et al. (2016) attributed the upward trend in tornado clusters to significant increases in storm relative helicity. However, the rise of tornado clusters could be related to changes in other environmental factors that influence the amount and intensity of deep convection.

To shed light on the possible reasons for this change, here we examine the relationships between collective tornado activity within a cluster and the associated environmental variables. Studies have identified environmental factors (such as convective available potential energy (CAPE), convective inhibition (CIN), bulk shear and storm-relative helicity) important to the development of tornadoes (Anderson-Frey et al., 2018; Cheng et al., 2016; Dean and Schneider, 2012; Jackson and Brown, 2009; Doswell III and Evans, 2003; Brown, 2002; Craven et al., 2002; Brooks et al., 1994; Gensini and Ashley, 2011). Missing from these studies is a quantification of the relationships between environmental factors and collective tornado activity. For example, how much CAPE is needed to produce a ten percent increase in accumulated tornado power (ATP)?

The objective here is to quantify the extent to which environmental factors influence ATP. We first identify the biggest days in the largest clusters of tornadoes. To quantify the relationships we regress ATP onto CAPE, CIN, stormrelative helicity, and bulk shear using tornadoes occurring on these big days. Values for the predictor variables are extracted from reanalysis data. Finally we examine model residuals for goodness of fit. The paper is outlined as follows.

The method to define tornado clusters and the selection criteria for determining the big days within large clusters are described in §2. Tornado power dissipation is defined and estimated in §3. The environmental variables are described in 


\section{IORNADO CLUSTERS}

\section{\begin{tabular}{l|l}
2.1 & Tornadoes
\end{tabular}}

A tornado can occur in isolation or within a cluster with other tornadoes. The American Meteorological Society formally defines a tornado outbreak as "multiple tornado occurrences associated with a particular synoptic-scale system" (American Meteorological Society, cited 2018). Less formally it is understood that an outbreak is a cluster of several to dozens of tornadoes that occur within a relatively short time scale and over a limited geographic region (Anderson-Frey et al., 2018; Malamud et al., 2016; Tippett et al., 2016; Elsner et al., 2015). We focus on tornado clusters in this work rather than on individual tornadoes because the larger spatial and temporal extents of clusters better match the scale represented by the environmental data. We refer to them as 'clusters' rather than 'outbreaks' because we make no attempt to associate the clusters with a particular synoptic-scale system.

Further, in this paper we consider only tornadoes occurring on convective days having at least ten tornadoes when those days are part of a cluster of at least 30 tornadoes. This requires a two step approach. In step one, each tornado is grouped in a cluster following the method outlined below. For step two, all days with at least ten tornadoes are extracted from clusters of 30 or more tornadoes. We obtain the tornado data from the Storm Prediction Center's extensive tornado record (https : //www.spc.noaa.gov/wcm/\#data). Date, time, and location of each tornado are used to delineate groups of tornadoes. The data are subset to include only contiguous United States tornadoes that occur from 1994 to 2017, inclusive. The start year marks the beginning of the extensive use of the WSR-88D radar. There are 29,372 tornadoes in the available record over this period of time.

\subsection{Group tornadoes into clusters}

First we project the geographic coordinates of the tornado locations using a Lambert conic conformal projection for the contiguous United States. The projection is needed to ensure correct distance measures. The projection origin is situated in eastern Kansas ( $39^{\circ} \mathrm{N}$ latitude and $96^{\circ} \mathrm{W}$ longitude). Then the Euclidean distance $\left(d_{i j}\right)$ between the genesis 
location of tornadoes $i$ and $j$ is computed for all tornado pairs. Similarly, the time separating each tornado pair $\left(t_{i j}\right)$ is computed and added to a scaled Euclidean distance to give a space-time difference $\left(\delta_{k}\right)$. The equation is

$$
\delta_{k}=d_{i j} / s+t_{i j}
$$

where $s$ is a scaling factor and where $k=n(n+1) / 2$ indexes the unique tornado pairs where $n$ is the number of tornadoes. The scaling factor is set to $15 \mathrm{~m} \mathrm{~s}^{-1}$ to match the units of $t_{i j}$ (seconds) and to approximately conform to the average speed of tornado-producing thunderstorms (although there is wide variation in this speed).

Next, the $k$ space-time differences $\left(\delta_{k}\right)$ are used to group the individual tornadoes into clusters. If tornado $i$ is close to tornado $j$ based on a small value of $\delta_{k}$, then the two tornadoes are considered to belong to the same cluster. Clustering is done using the single-linkage method whereby the two tornadoes with the smallest $\delta_{k}$ are grouped first. Then the two tornadoes (or the first tornado cluster and another tornado) with the next smallest $\delta_{k}$ are grouped second. The procedure continues by grouping tornado pairs, cluster-tornado pairs, and cluster-cluster pairs until there is a single large cluster. A cluster-tornado pair occurs when the shortest distance is between the closest tornado in the cluster and a tornado not in the cluster. For example, three tornadoes each $100 \mathrm{~km}\left(\sim 2\right.$ hours at $\left.15 \mathrm{~m} \mathrm{~s}^{-1}\right)$ apart occurring at the same time are considered a cluster. A fourth tornado is considered in the cluster if it is no more than $100 \mathrm{~km}$ from any one of the other three tornadoes. The grouping is done with the hclust function from the stats package in $R$.

Our interest centers on clusters that are not too small (e.g., a family of tornadoes from a single supercell) and not too large (e.g., all tornadoes during a week). So we stop grouping once there are no additional pairs within a $\delta_{k}$ of $50 \mathrm{~K}$ seconds ( 14 hours). This results in 6,156 unique clusters and 155 large (at least 30 tornadoes) clusters. The largest cluster occurred from April 26-28, 2011. It contains 293 tornadoes. Duration of the clusters ranges from 46 one-day clusters to one five-day cluster (Table 1). Multi-day clusters account for $70.3 \%$ of all our clusters. The cluster with the longest duration occurred from September 4-8, 2004 and contained 103 tornadoes (Fig. 1). Our clusters match the outbreaks identified subjectively by Forbes (2006) with an agreement rate of $88 \%$. 


\subsection{Select tornadoes from large clusters on days with at least ten tornadoes}

Our objective is to quantify the extent to which well-known environmental factors statistically explain tornado activity at an aggregate level as measured by the ATP dissipation. Since some of the environmental factors have large diurnal fluctuations that can confound a multi-day analysis, we narrow our focus even more by considering only the most prolific days in these largest groups. We define the day as the 24-hour period starting at 6 AM local time (often referred to as the 'convective' day) (Doswell et al., 2006). A big convective day (big day) as part of a large cluster is defined as one with at least ten tornadoes.

With this definition, we find 212 big days within our large clusters. Note that there are sometimes more than one big day in a single large cluster. Also, ten or more tornadoes can occur within smaller clusters, and our set of big days accounts for only $28.6 \%$ of all days with at least ten tornadoes. The top two big days (April 26, 2011, and April 27, 2011) are associated with the largest tornado cluster (Table 2). Note that this set of big days identified and analyzed in this paper is unchanged for values of $s$ (Eq. 1) ranging between 8 and $20 \mathrm{~m} \mathrm{~s}^{-1}$.

Figure 2 is an example of a big day in a large cluster. There were 88 tornadoes on that day. The cluster is identified as the eighth most prolific by our method (and the first most prolific by Forbes (2006)) and extended over a two convective day period beginning on May 30th. This is the seventh largest of our big days as defined by the number of tornadoes in any large cluster.

Most big days occur east of the Rockies and west of the Appalachians depicted by the centroids (Fig. 3). In particular, there is a group of centroids that spans the middle South extending northwestward toward the central Great Plains. There is also a tendency for days having the most tornadoes to occur farther to the east. The overall pattern of cluster centroids is similar to the pattern shown in Anderson-Frey et al. (2018), who used kernel density to define the clusters.

\section{3 | ACCUMULATED TORNADO POWER}

We use tornado counts to define clusters and big days but our interest is on the accumulated power dissipated over all tornadoes occurring during a big day. The standard indicator of tornado strength is the Enhanced Fujita scale (Malamud and Turcotte, 2012), but path length and width are sometimes used to compute other intensity metrics (Brooks et al., 2003; Fuhrmann et al., 2014; Malamud and Turcotte, 2012). Over a cluster of tornadoes, the Destructive Potential Index (DPI) has been used as a measure of the potential for damage and casualties (Thompson and Vescio, 1998). The adjusted 
Fujita mile is a collective measure that uses the highest EF rating multiplied by the tornado track length (Fuhrmann et al., 2014).

Here we follow the work of Fricker et al. (2017) in defining the power dissipation $(E)$ of a tornado as the potential of the wind to inflict damage to objects on the surface. It is calculated using damage path area $\left(A_{p}\right)$, air density $(\rho)$, midpoint wind speed $\left(v_{j}\right)$ for each EF rating $(j=0, \cdots, J$, where $J$ is the maximum EF rating), and the fraction of the damage path $\left(w_{j}\right)$ associated with each rating. $E$ is strongly correlated to DPI but more useful here because it is an extensive variable. As such we sum $E$ over all tornadoes occurring during a big day to get the accumulated tornado power (ATP). Mathematically, we express $E$ and ATP as:

$$
\begin{aligned}
E & =A_{p} \rho \sum_{j=0}^{J} w_{j} v_{j} \\
\mathrm{ATP} & =\sum_{i=1}^{n} E_{i}
\end{aligned}
$$

where $n$ is the number of tornadoes occurring in the big day.

ATP is calculated using path width and the highest EF rating of each tornado on the big day. Therefore, ATP is considered a maximum estimate of power dissipation on a given day. The reporting of path width changed from an 'average' to the maximum in 1994. Our study starts with 1994 and so it is not impacted by this change. A list of the top ten big days in large clusters by ATP includes the infamous days of April 27, 2011 and May 4, 2003 (Table 2).

The ATP on April 27, 2011 is nearly four times the ATP on the next most powerful day (April 26, 2011). The Spearman rank correlation between ATP and the number of tornadoes is 0.63 . Big days occurring as part of a large cluster occur during April through June (Table 3). July and August have the fewest big days. Monthly average ATP peaks in April with the next highest months being March and May. May and November have similar values of average ATP. There are fewer big tornado days during November, but when they occur they tend to include stronger tornadoes with longer paths leading to more ATP. 


\section{ENVIRONMENTAL VARIABLES}

To quantify the relationship between ATP and environmental factors on big days we obtain environmental variables from the National Center for Environmental Prediction's (NCEP) North American Regional Reanalysis (NARR). The data are available from the National Center for Atmospheric Research (NCAR). Variables from the NARR have been used previously to analyze convective environments (Brooks et al., 2003; Gensini and Ashley, 2011; Mesinger et al., 2006). Tornado environments have been studied without NARR using proximity soundings and weather stations (Potvin et al., 2010). Here we are interested in aggregate tornado activity occurring over a broad spatial scale so the NARR variables are used rather than proximity soundings.

We use the original NARR 3-hourly files containing environmental data for each convective day starting with 12 UTC in 3-hour increments. For each big day, we choose the closest time before the occurrence of the first tornado (Table 4). As an example, if the first tornado in the cluster occurred at $1730 \mathrm{Z}$ then $15 Z$ would be chosen because it is the closest 3-hour NARR time prior to start of this event. This allows us to capture the environment before the occurrence of tornadoes. The majority of times selected are between 12 UTC and 21 UTC with the peak occurring at 12 UTC.

Each NARR file contains 434 atmospheric variables. We consider only a small subset of the the variables representing convective instability and wind shear including the 180 to $0 \mathrm{hPa}$ above ground level (AGL) CAPE and CIN (layer 375,376 ), the 0 to $3000 \mathrm{~m} \mathrm{AGL}$ storm-relative helicity (layer 323), and the 0 to $6000 \mathrm{~m} \mathrm{AGL} u$ and $v$ components of storm motion (layer 324, 325). Additionally, we download the $u$ and $v$ components of wind for the $1000 \mathrm{hPa}$ (layer 260 , 261) and $500 \mathrm{hPa}($ layer 117,118$)$ levels. We compute total storm motion as the square root of the sum of the velocity components squared. We compute the bulk shear as the square root of the sum of the squared differences between the $u$ and $v$ components of the wind at $1000 \mathrm{hPa}$ and $500 \mathrm{hPa}$ levels. We choose these variables because they are well known to be associated with tornado development (Brooks et al., 1994; Jackson and Brown, 2009; Brown, 2002; Craven et al., 2002; Dean and Schneider, 2012; Anderson-Frey et al., 2018; Doswell III and Evans, 2003; Cheng et al., 2016).

Selected and computed NARR variables are available in the form of a 277 by 349 rectangular raster. The corresponding big day convex hull encompassing the tornado genesis locations is used as a spatial mask, and the raster values falling under the mask are reduced to a single value. For the variables CAPE, bulk shear, and storm-relative helicity, the reduction consists of taking the highest value under the mask. For CIN the reduction consists of taking the smallest value under the mask (Fig. 4). In this way, every big day value of ATP is associated with one value for each of the environmental variables. The single highest (or lowest) value ensures that the unstable air mass is represented. The use 
of a maximum and minimum value for each environmental variable is less contaminated by other synoptic and mesoscale processes leading to a more representative tornado environment. To varying degrees this approach distinguishes the environmental variables when considering extremes in ATP (Table 5). This ability to distinguish extremes in ATP is particularly true for bulk shear and, to a lesser extent, CAPE and foreshadows the regression results presented next.

\section{5 | QUANTIFYING THE RELATIONSHIP BETWEEN ATP AND ENVIRONMEN- TAL FACTORS}

We use our collated data representing 212 big days to regress ATP onto the environmental variables whose values are chosen within the area defined by the tornado cluster as described above. The regression model quantifies the effect of each environmental variable on ATP while holding the other variables constant. Due to the large seasonal variability in ATP (Table 3), the month of the big day occurrence is included as a random effect (an offset to the intercept term). Environmental variables are considered fixed effects as is the year during which the big day occurred. Year is included as a fixed effect because ATP is increasing over time (Elsner et al., 2018). If year is not included in the model, the increasing trend could confound the influence of the other fixed effects. The coefficient on year is the annual trend.

Values of ATP are skewed to the right with most big days having less than 5 TW of ATP. However, the top ten days have more than 30 TW each of ATP with the top day having 221 TW. The distribution of ATP on a log scale is nearly symmetric about the mean value of 7.8 TW. The median value is 3.2 TW, and the geometric mean is 2.6 TW. So, the model uses the logarithm of ATP as the response variable. Mathematically the model is given by

$$
\begin{aligned}
\operatorname{In}\left(\text { ATP }_{i}\right)= & \beta_{0}+\beta_{\text {Year } \text { Year }_{i}+\beta_{\text {CAPE CAPE }}} \\
& \beta_{\text {Shear } \text { Shear }_{i}+\beta_{\text {Helicity }} \text { Helicity }_{i}+\beta_{\mathrm{CIN} \mathrm{CIN}_{i}+}} \\
& \beta_{\text {Month }\left(1 \mid \text { Month }_{i}\right)+\epsilon_{i},}
\end{aligned}
$$

where the $\beta_{\text {Year }}, \beta_{\mathrm{CAPE}}, \beta_{\text {Shear }} \beta_{\text {Helicity }}, \beta_{\mathrm{CIN}}$ and $\beta_{\text {Month }}$ are the model coefficients. Month is a random effect as mentioned above so $\beta_{\text {Month }}$ is a vector of coefficients with one element for each month of the year. To make interpreting the coefficients easier, we divide the values of CAPE by 1000 , storm-relative helicity and CIN by 100 , and bulk shear by 10 . The coefficients are determined via an interactive maximum likelihood approach with the lmer 
function from the lme4 package for R (Bates et al., 2015).

The regression model is best in the sense that it has the lowest Akaike Information Criterion (AIC) score, which measures the overall quality (goodness of fit and simplicity) of the model. Due to a large correlation between bulk shear and relative storm motion (0.55) we retain only bulk shear in the model. We determined that interactions between the environmental variables did not improve the model fit based on higher AIC scores when they were included. We also determined that using spatially averaged values for the environmental variables in place of the maximum values makes the fit worse. The maximum (and minimum) values within the cluster area provide a better representation of the environmental conditions for the tornadoes on each big day because they are less contaminated by synoptic and mesoscale features.

The model has a log-additive structure indicating that the logarithm of ATP is related to the fixed and random effects in an additive way. So the interpretation of the coefficients are given in terms of a percent change per unit change in the effect. The coefficient on the year term ( $\left.\beta_{\text {Year }}\right)$ indicates an upward trend in per big-day outbreak ATP amounting to $5 \%[(2 \%, 8 \%), 95 \%$ uncertainty interval (UI)] per year holding the environmental variables constant (Table 6). Note that the percent increase is calculated using $\left(e^{\beta} Y e a r-1\right) \times 100 \%$. The upward trend is consistent with the results of Elsner et al. (2018) using all tornadoes.

Physically the model coefficients on the environmental variables are reasonable and consistent with expectations given present understanding of factors that influence tornado activity. Specifically, an increase in ATP is statistically explained by increasing values of CAPE, bulk shear, and storm-relative helicity and by decreasing values of CIN. Bulk shear has the largest influence on ATP as seen by its corresponding $t$ value. Quantitatively, the coefficient on the CAPE term ( $\left.\beta_{\text {CAPE }}\right)$ indicates that ATP increases by 33\% [(11\%, 46\%), 95\% UI] for every $1000 \mathrm{~J} \mathrm{~kg}^{-1}$ increase in CAPE, holding the other variables and year constant. The coefficient on the bulk shear term ( $\beta_{\text {Shear }}$ ) indicates that ATP increases by $125 \%$ for every $10 \mathrm{~m} \mathrm{~s}^{-1}$ increase in the magnitude of bulk shear. The coefficient on the storm-relative helicity term ( $\left.\beta_{\text {Helicity }}\right)$ indicates that ATP increases by $12 \%$ for every $100 \mathrm{~m}^{2} \mathrm{~s}^{-2}$ increase in storm-relative helicity and the coefficient on the $\mathrm{CIN}$ term $\left(\beta_{\mathrm{CIN}}\right)$ indicates that ATP decreases by $8 \%$ for every $100 \mathrm{~J} \mathrm{~kg}^{-1}$ increase in $\mathrm{CIN}$, when the other variables are held constant.

The correlation between observed and modeled estimated ATP is a modest 0.37 . We compute the conditional standardized residuals (Santos Nobre and da Motta Singer, 2007) between the actual and estimated values of ATP. A histogram of the residuals is adequately described by a normal distribution, and a plot of the residuals as a function of the model estimated values by month shows no apparent pattern (Fig. 5) both indicative of an adequate model. 
We illustrate the model by estimating ATP across a range of CAPE and bulk shear values with CIN and storm-relative helicity values set to their respective means $\left(-200 \mathrm{~J} \mathrm{~kg}^{-1}\right.$ and $\left.40 \mathrm{~m}^{2} \mathrm{~s}^{-2}\right)$, with year set 2017 , and with month set to April (Figure 6). Year is set to 2017 because it is the last year in the data used, and month is set to April because it is the month during which ATP is highest on average. Estimates show that ATP increases with increasing values of CAPE and bulk shear. With a CAPE of $250 \mathrm{~J} \mathrm{~kg}^{-1}$ and a bulk shear of $25 \mathrm{~m} \mathrm{~s}^{-1}$ the model estimates an ATP of 2.49 TW. In comparison, with a CAPE of $3000 \mathrm{~J} \mathrm{~kg}^{-1}$ and a bulk shear of $15 \mathrm{~m} \mathrm{~s}^{-1}$ the model estimates an ATP of 2.40 TW. In contrast, with a CAPE of $4000 \mathrm{~J} \mathrm{~kg}^{-1}$ and a bulk shear of $40 \mathrm{~m} \mathrm{~s}^{-1}$, the model estimates an ATP of $24.3 \mathrm{TW}$. We can estimate values of ATP for other values of the predictors.

Figure 7 shows the actual versus estimated ATP for the 212 big tornado days. Darker blue points, which tend to be associated with higher values of ATP, indicate more casualties (death plus direct injuries). Increases in CAPE and bulk shear lead to more and stronger tornadoes with increased potential for casualties. The points on the graph tend to fall along a line from lower left to upper right but with a slope less than one. Big tornado days that have more ATP than what the model estimates are points that fall below the diagonal. We note that April 27, 2011, and April 26, 2011, are examples of days with more ATP than estimated by the model, and April 19, 2011, and February 20, 2014, are examples of days with less ATP than estimated by the model. We plot the convex hull of the tornado genesis locations on the days with the most over- and under-estimated ATP (Fig. 8). There is no distinction in the size of the areas between these two cases but cases of under estimation are noted across the central Plains where there are no cases of over estimation.

The average number of tornadoes per unit area during big days that are most under-estimated is 2.4 per square kilometer compared to 1.7 per square kilometer during big days that are most over-estimated. The average area of the under-estimated days is 49.4 square kilometer compared to 34.7 square kilometer for over-estimated days. This implies that the model might be improved by including environmental factors that explain the localized efficiency of tornado production.

\section{6 | SUMMARY AND CONCLUSIONS}

April 27, 2011 was the biggest day in the largest, costliest, and one of the deadliest tornado outbreaks ever recorded in the United States (Knox et al., 2013). The multi-day event affected 21 states from Texas to New York. Recent studies show an increasing tendency for a higher proportion of tornadoes occurring in large outbreaks. To shed light on why 
this might be happening, here we quantified the relationship between convective environmental variables and ATP during days with many tornadoes that occurred in large multi-day clusters.

First, using single-linkage clustering and filtering we identified all days over the period 1994-2017 having ten or more tornadoes that occurred within multi-day clusters having 30 or more tornadoes. Then, for each big day, we computed ATP as the sum of the power dissipated over all tornadoes occurring on that day (starting at 12 UTC). Next, we identified the extremes in CAPE, CIN, bulk shear, and storm-relative helicity over the area defined by the tornado genesis locations and by the time before the occurrence of the first tornado. Finally, for the set of 212 big days, the logarithm of ATP was regressed onto the environmental factors and year using a mixed effects model with the month of the day as a random effect. Results show an upward trend in ATP at a rate of $5 \%$ per year. They also showed that, on average, ATP increases with additional bulk shear, CAPE, and storm-relative helicity and decreased with additional CIN. Model residuals were analyzed to determine the adequacy of the model and to identify the largest under and over estimations.

The major conclusions are:

- An objective technique can reliably identify known tornado clusters.

- Accumulated tornado power (ATP) is a useful measure of cluster severity.

- On average cluster severity increases by $125 \%$ for every $10 \mathrm{~m} \mathrm{~s}^{-1}$ increase in bulk shear holding the other variables constant.

- On average cluster severity increases by $33 \%$ for every $1000 \mathrm{~J} \mathrm{~kg}^{-1}$ increase in CAPE holding the other variables constant.

- The number of tornadoes per unit area is larger on days when the model under estimates cluster severity.

Since bulk shear has the largest influence on ATP, long-term changes to it might help explain the documented changes in tornado activity. Our results are consistent with Tippett et al. (2016) in that both highlight the importance of shear on tornado activity. The correlation between ATP and model estimated ATP is a modest 0.37 , but this level of correspondence indicates some practical value to the approach (see Cohen et al. (2018)). Results from this study are limited by sample size (we only had 212 big days) and by an exclusive focus on the last 20 years of a much longer tornado record. They are also limited by the quality of the NARR data, which tends to unrealistically favor environments for tornadoes in certain convective setups (Gensini and Ashley, 2011; Gensini et al., 2014; Allen et al., 2015). The 
250

study could be improved by considering more cases from earlier years. The cost of including earlier data would be greater uncertainty on the estimates of power dissipation. The model can almost certainly be improved by including other environmental factors, especially ones that are related to the convective mode and to the efficiency of tornado production. Future work will examine the spatial variation in the factors affecting cluster severity and will quantify the relationship between cluster aggregated casualties and the environmental factors controlling for how many people were within the 'outbreak' area.

\section{ACKNOWLEDGEMENTS}

The code and data to produce all the figures and results of this paper are available at https://github.com/jelsner/ tor-clusters. 


\section{REFERENCES}

Allen, J. T., Tippett, M. K. and Sobel, A. H. (2015) Influence of the El Niño/Southern Oscillation on tornado and hail frequency in the United States. Nature Geosciences, 8, 278-283.

American Meteorological Society (cited 2018) Tornado Outbreak, Glossary of Meteorology. [Available online at http:// glossary. ametsoc.org/wiki/Citation].

Anderson-Frey, A. K., Richardson, Y. P., Dean, A. R., Thompson, R. L. and Smith, B. T. (2018) Near-storm environments of outbreak and isolated tornadoes. Weather and Forecasting, 33, 1397-1412. URL: https://doi.org/10.1175/WAF-D-180057.1.

Bates, D., Mächler, M., Bolker, B. and Walker, S. (2015) Fitting linear mixed-effects models using Ime4. Journal of Statistical Software, 67, 1-48.

Brooks, H. E., Carbin, G. W. and Marsh, P. T. (2014) Increased variability of tornado occurrence in the United States. Science, 346, 349-352. URL: https://science. sciencemag.org/content/346/6207/349.

Brooks, H. E., Doswell, C. A. and Cooper, J. (1994) On the environments of tornadic and nontornadic mesocyclones. Weather and Forecasting, 9, 606-618.

Brooks, H. E., Lee, J. W. and Craven, J. P. (2003) The spatial distribution of severe thunderstorm and tornado environments from global reanalysis data. Atmospheric Research, 67, 73-94.

Brown, M. (2002) The spatial, temporal, and thermodynamic characteristics of southern-Atlantic United States tornado events. Physical Geography, 23, 401-417.

Cheng, V. Y. S., Arhonditsis, G. B., Sills, D. M. L., Gough, W. A. and Auld, H. (2016) Predicting the climatology of tornado occurrences in North America with a Bayesian hierarchical modeling framework. Journal of Climate, 29, 1899-1917.

Cohen, A. E., Cohen, J. B., Thompson, R. L. and Smith, B. T. (2018) Simulating tornado probability and tornado wind speed based on statistical models. Weather and Forecasting, 33, 1099-1108. URL: https://doi .org/10.1175/waf-d-17-0170.1.

Craven, J. P., Jewell, R. E. and Brooks, H. E. (2002) Comparison between observed convective cloud-base heights and lifting condensation level for two different lifted parcels. Weather and Forecasting, 17, 885-890.

Dean, A. R. (2010) P2.19 An analysis of clustered tornado events. In 25th Conference on Severe Local Storms.

Dean, A. R. and Schneider, R. S. (2012) P60 An examination of tornado environments, events, and impacts from 2003 - 2012. In 26th Conference on Severe Local Storms. 
Dixon, P. G., Mercer, A. E., Grala, K. and Cooke, W. H. (2014) Objective identification of tornado seasons and ideal spatial smoothing radii. Earth Interactions, 18, 1-15.

Doswell, C. A., Edwards, R., Thompson, R. L., Hart, J. A. and Crosbie, K. C. (2006) A simple and flexible method for ranking severe weather events. Weather and Forecasting, 21, 939-951. URL: https://doi .org/10.1175/waf959.1.

Doswell III, C. and Evans, J. (2003) Proximity sounding analysis for derechos and supercells: An assessment of similarities and differences. Atmospheric Research, 67-68, 117-133.

Elsner, J. B., Elsner, S. C. and Jagger, T. H. (2015) The increasing efficiency of tornado days in the United States. Climate Dynamics, 45, 651-659.

Elsner, J. B., Fricker, T. and Schroder, Z. (2018) Increasingly powerful tornadoes in the United States. Geophysical Research Letters, 46, 392-398.

Forbes, G. S. (2006) Meteorological aspects of high-impact tornado outbreaks. In Preprints, 22nd Conf. on Severe Local Storms, 1-12. Hyannis, MA: Amer. Meteor. Soc.

Fricker, T., Elsner, J. B. and Jagger, T. H. (2017) Population and energy elasticity of tornado casualties. Geophysical Research Letters, 44, 3941-3949.

Fuhrmann, C. M., Konrad II, C. E., Kovach, M. M., McLeod, J. T., Schmitz, W. G. and Dixon, P. G. (2014) Ranking of tornado outbreaks across the United States and their climatological characteristics. Weather and Forecasting, 29, 684-701.

Galway, J. G. (1977) Some climatological aspects of tornado outbreaks. Monthly Weather Review, 105, 477-484.

Gensini, V. and Ashley, W. (2011) Climatology of potentially severe convective environments from the North American Regional Reanalysis. Electronic Journal of Severe Storms Meteorology, 6, 1-40.

Gensini, V. A., Mote, T. L. and Brooks, H. E. (2014) Severe-thunderstorm reanalysis environments and collocated radiosonde observations. Journal of Applied Meteorology and Climatology, 53, 742-751. URL: https://doi.org/10.1175/JAMC-D-130263.1.

Jackson, J. D. and Brown, M. E. (2009) Sounding-derived low-level thermodynamic characteristics associated with tornadic and non-tornadic supercell environments in the Southeast United States. National Weather Digest, 33, 16-26.

Knox, J. A., Rackley, J. A., Black, A. W., Gensini, V. A., Butler, M., Dunn, C., Gallo, T., Hunter, M. R., Lindsey, L., Phan, M., Scroggs, R. and Brustad, S. (2013) Tornado debris characteristics and trajectories during the 27 April 2011 super outbreak as determined using social media data. Bulletin of the American Meteorological Society, 94, 1371-1380.

Knupp, K. R., Murphy, T. A., Coleman, T. A., Wade, R. A., Mullins, S. A., Schultz, C. J., Schultz, E. V., Carey, L., Sherrer, A., McCaul, E. W. and et al. (2014) Meteorological overview of the devastating 27 April 2011 tornado outbreak. Bulletin of the American Meteorological Society, 95, 1041-1062. 
Malamud, B. D. and Turcotte, D. L. (2012) Statistics of severe tornadoes and severe tornado outbreaks. Atmospheric Chemistry and Physics, 12, 8459-8473.

Malamud, B. D., Turcotte, D. L. and Brooks, H. E. (2016) Spatial-temporal clustering of tornadoes. Natural Hazards and Earth System Sciences, 16, 2823-2834.

Mercer, A. E., Shafer, C. M., Doswell III, C. A., Leslie, L. M. and Richman, M. B. (2009) Objective classification of tornadic and nontornadic severe weather outbreaks. Monthly Weather Review, 137, 4355-4368.

Mesinger, F., DiMego, G., Kalnay, E., Mitchell, K., Shafran, P. C., Ebisuzaki, W., Jović, D., Woollen, J., Rogers, E., Berbery, E. H., Ek, M. B., Fan, Y., Grumbine, R., Higgins, W., Li, H., Lin, Y., Manikin, G., Parrish, D. and Shi, W. (2006) North American Regional Reanalysis. Bulletin of the American Meteorological Society, 87, 343-360. URL: https://doi .org/10.1175/BAMS-87-3-343.

Moore, T. (2017) On the temporal and spatial characteristics of tornado days in the United States. Atmospheric Research, 184, 56-65.

- (2018) Annual and seasonal tornado trends in the contiguous United States and its regions. International Journal of Climatology, 38.

Moore, T. W. and DeBoer, T. A. (2019) A review and analysis of possible changes to the climatology of tornadoes in the United States. Progress in Physical Geography: Earth and Environment, 43, 365-390. URL: https://doi.org/10.1177/ 0309133319829398.

Potvin, C., Elmore, K. and J. Weiss, S. (2010) Assessing the impacts of proximity sounding criteria on the climatology of significant tornado environments. Weather and Forecasting, 25, 921-930.

Santos Nobre, J. and da Motta Singer, J. (2007) Residual analysis for linear mixed models. Biometrical Journal, 49, 875-875. URL: https://doi.org/10.1002/bimj .200790008.

Schneider, R. S., Brooks, H. E. and Schafer, J. T. (2004) Tornado outbreak day sequences: Historic events and climatology (18752003). In Preprints, 22nd Conf. on Severe Local Storms, 1-11. Hyannis, MA: Amer. Meteor. Soc.

Thompson, R. and Vescio, M. (1998) The Destruction Potential Index - A method for comparing tornado days. In 19th Conference on Severe Local Storms.

Tippett, M. K., Lepore, C. and Cohen, J. E. (2016) More tornadoes in the most extreme U.S. tornado outbreaks. Science, 354, 1419-1423. URL: https://doi.org/10.1126/science.aah7393.

Tippett, M. K., Sobel, A. H. and Camargo, S. J. (2012) Association of U.S. tornado occurrence with monthly environmental parameters. Geophysical Research Letters, 39, L02801. 
344

Tippett, M. K., Sobel, A. H., Camargo, S. J. and Allen, J. T. (2014) An empirical relation between U.S. tornado activity and monthly environmental parameters. Journal of Climate, 27, 2983-2999.

Trapp, R. (2014) On the significance of multiple consecutive days of tornado activity. Monthly Weather Review, 142, 14521459. 


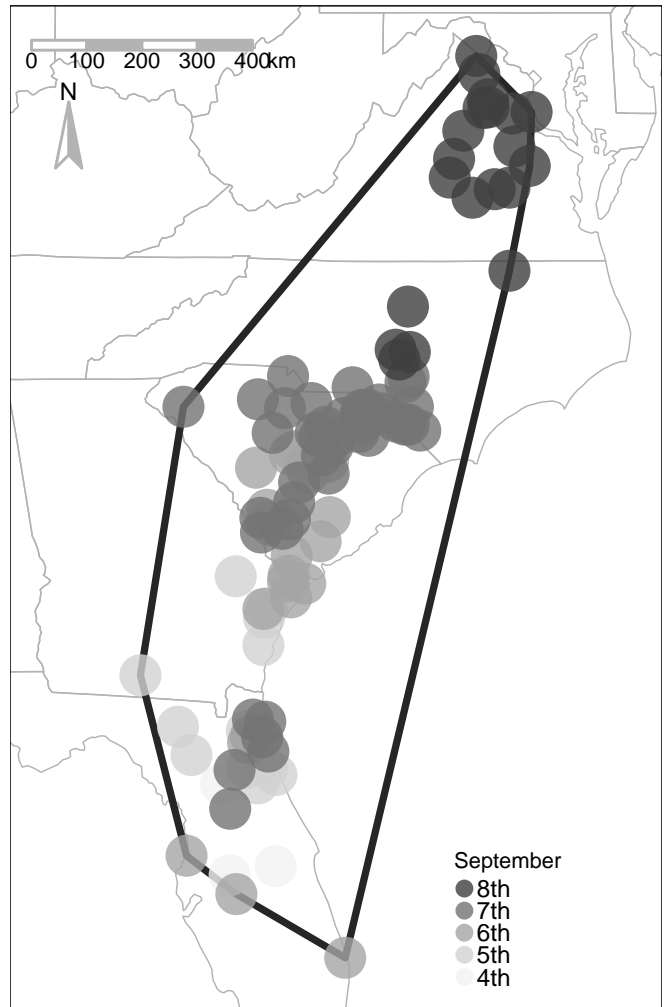

FIGURE 1 A cluster of tornadoes in 2004 that occurred between September 4th and September 8th. Each circle is a tornado genesis location colored by the day of occurrence. The black line is the minimum convex polygon surrounding all the genesis locations (convex hull) 


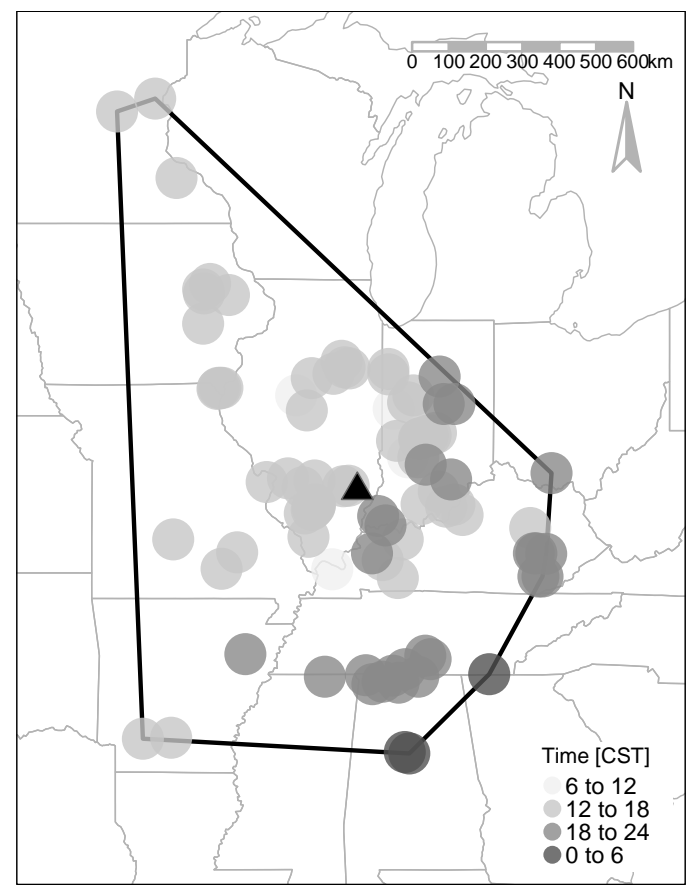

FI G URE 2 Tornadoes on May 30, 2004 as part of a big day within a large cluster. Each point represents a genesis location and is colored by the hour it occurred. The black triangle is the geographic center of the genesis locations. The black line is the minimum convex polygon around the genesis locations (convex hull). 


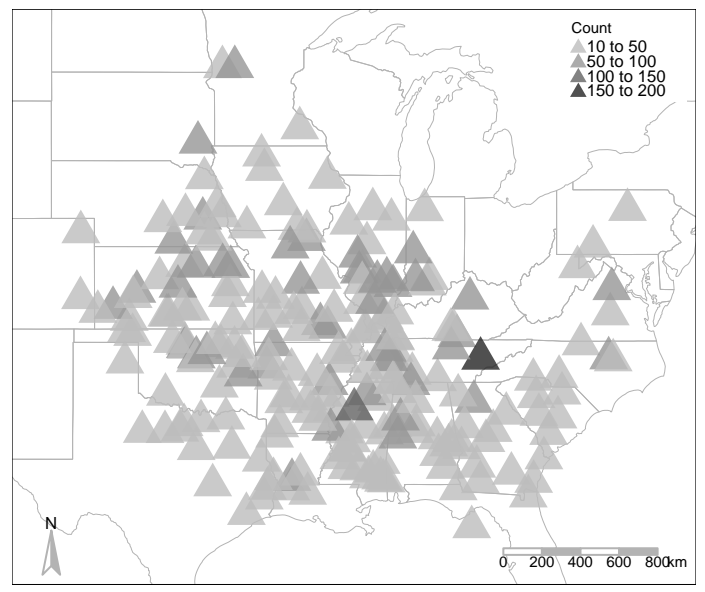

FIGURE 3 Centroids of genesis locations occurring on big days in large clusters. Triangles are colored by the number of tornadoes on that day. 

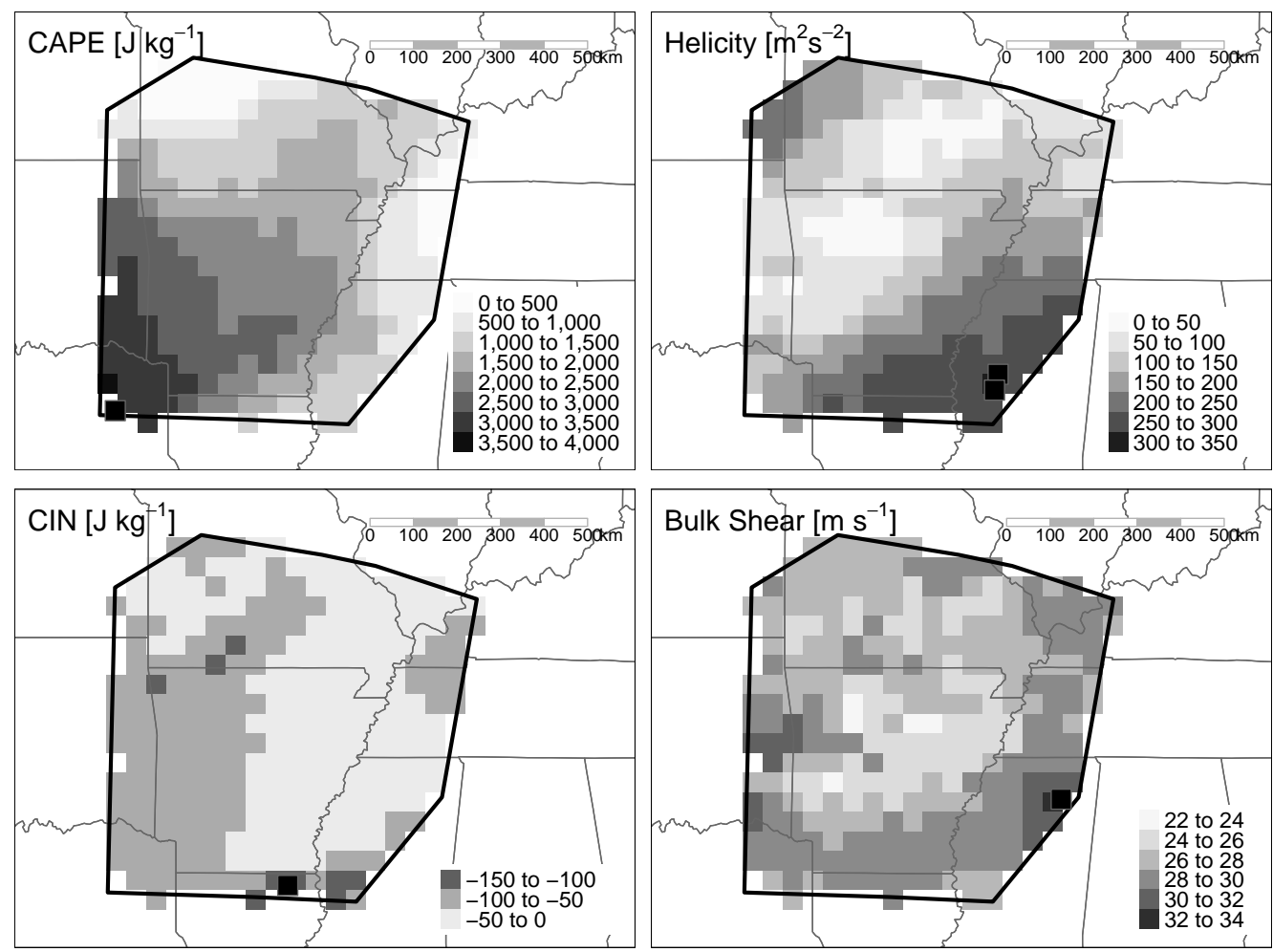

FIGURE 4 Environmental conditions at 12 UTC on May 6, 2003. The black line is the spatial extent of the tornado genesis locations. The first tornado in the cluster started at 14:20 UTC. The black square indicates the locations of the highest value of CAPE (3660 $\left.\mathrm{J} \mathrm{kg}^{-1}\right)$, the lowest value of CIN $\left(-149 \mathrm{~J} \mathrm{~kg}^{-1}\right)$, the highest value of storm-relative helicity $\left(308 \mathrm{~m}^{2} \mathrm{~s}^{-2}\right)$ and the highest value of bulk shear $\left(33 \mathrm{~m} \mathrm{~s}^{-1}\right)$. 
A

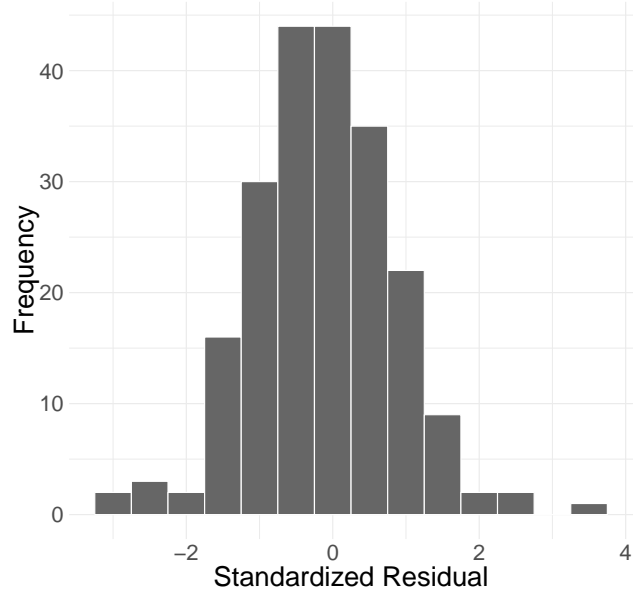

B

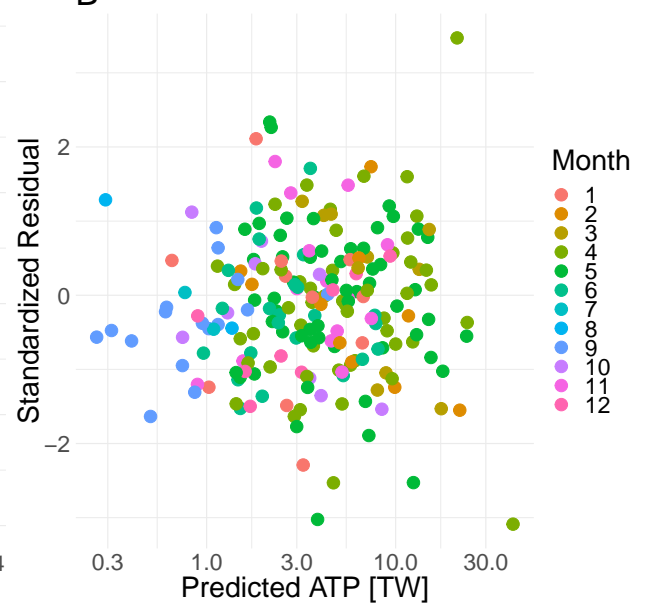

F I GURE 5 Conditional standardized residuals from the linear regression model. (A) Histogram and (B) Residuals as a function of modeled estimated values of ATP. 


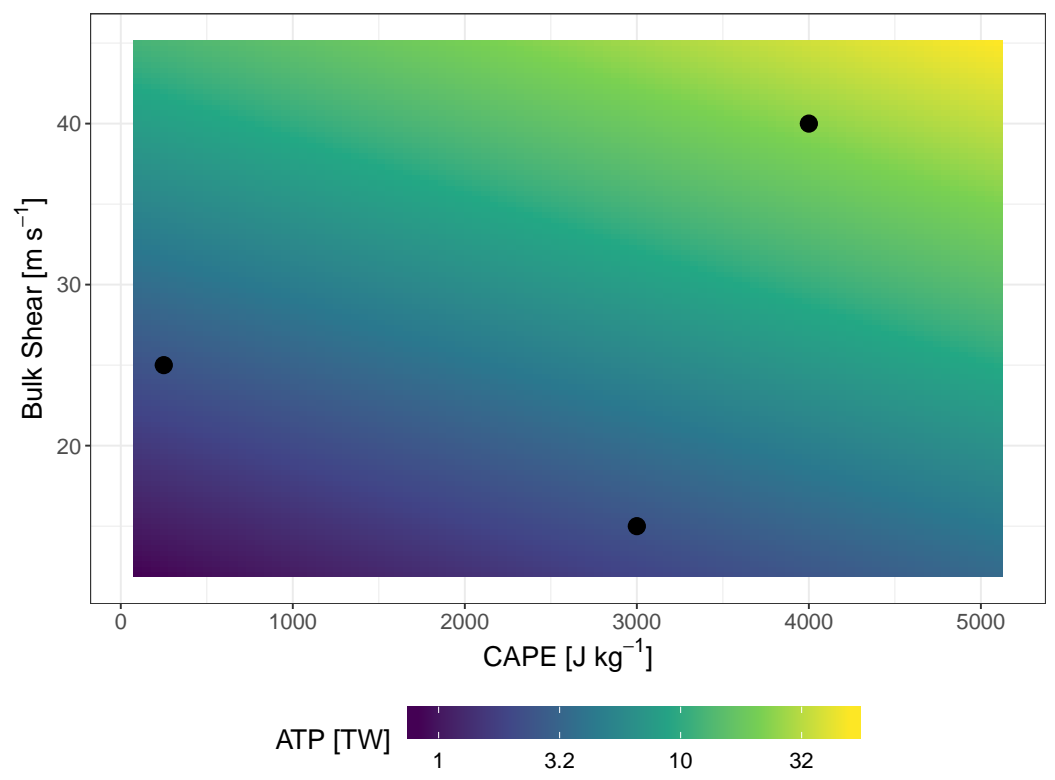

FIGURE 6 Model estimates of ATP across a range of CAPE and bulk shear values holding CIN, and storm-relative helicity at their average values and setting year to 2017 and month to April. The estimates are from an application of the regression model (Eq. 3) with coefficients given in Table 6. 


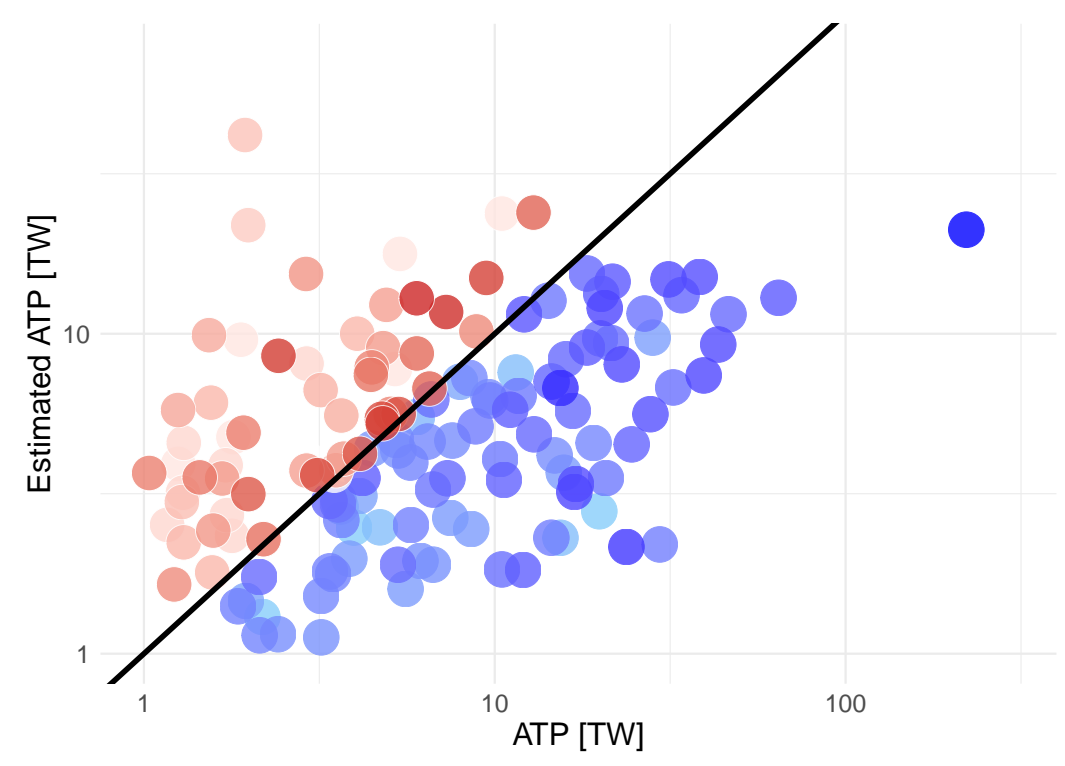

FIGURE 7 Actual versus estimated ATP on the big tornado days. The color shading from dark to light indicates an increasing number of casualties. 


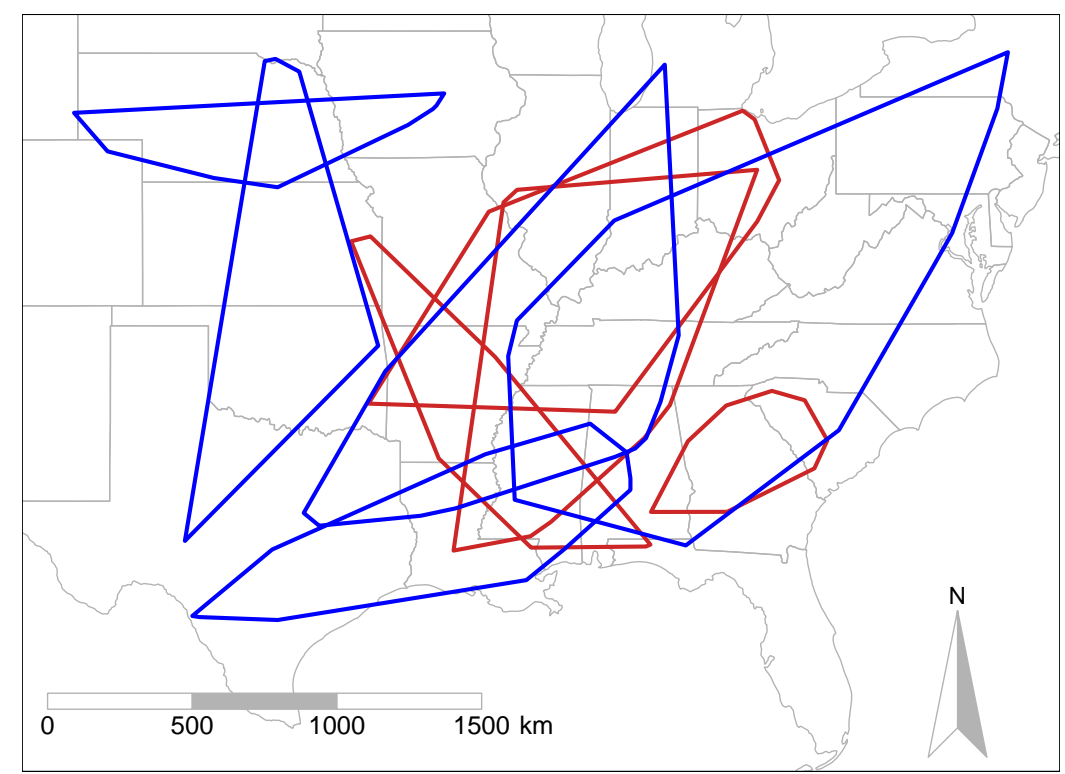

FIGURE 8 Areas defining the boundary of tornadoes on big days. Days selected are those when the regression model most under estimated ATP (blue) and when the regression model most over estimated ATP (red). 


\begin{tabular}{|c|c|c|}
\hline $\begin{array}{c}\text { Duration } \\
\text { (days) }\end{array}$ & $\begin{array}{c}\text { Number of } \\
\text { Large Groups }\end{array}$ & $\begin{array}{c}\text { Number of } \\
\text { Tornadoes }\end{array}$ \\
\hline 1 & 46 & 2024 \\
\hline 2 & 83 & 4461 \\
\hline 3 & 22 & 1620 \\
\hline 4 & 3 & 197 \\
\hline 5 & 1 & 103 \\
\hline
\end{tabular}

TAB LE 1 The total number of large groups and tornadoes by duration. 


\begin{tabular}{|c|c|c|c|}
\hline $\begin{array}{c}\text { Big Day } \\
\text { in Large Cluster }\end{array}$ & $\begin{array}{c}\text { Number of } \\
\text { Tornadoes }\end{array}$ & $\begin{array}{c}\text { Number of } \\
\text { Casualties }\end{array}$ & $\begin{array}{c}\text { ATP } \\
\text { (TW) }\end{array}$ \\
\hline April 27, 2011 & 173 & 3069 & 221 \\
\hline April 26, 2011 & 104 & 97 & 46 \\
\hline January 21, 1999 & 99 & 171 & 12 \\
\hline June 24, 2003 & 94 & 12 & 3 \\
\hline May 5, 2007 & 90 & 24 & 8 \\
\hline May 25, 2011 & 90 & 23 & 9 \\
\hline May 30, 2004 & 88 & 46 & 2 \\
\hline May 4, 2003 & 86 & 384 & 31 \\
\hline February 5, 2008 & 85 & 482 & 39 \\
\hline April 14, 2012 & 84 & 79 & 32 \\
\hline
\end{tabular}

TAB LE 2 Top ten big days in large tornado clusters with 30 or more tornadoes. ATP is the accumulated tornado power. 


\begin{tabular}{|c|c|c|c|}
\hline Month & $\begin{array}{c}\text { Average } \\
\text { ATP (TW) }\end{array}$ & $\begin{array}{c}\text { Number of } \\
\text { Tornadoes }\end{array}$ & $\begin{array}{c}\text { Number of } \\
\text { Big Days }\end{array}$ \\
\hline January & 4.72 & 416 & 11 \\
\hline February & 7.20 & 333 & 10 \\
\hline March & 12.60 & 444 & 11 \\
\hline April & 13.10 & 2022 & 50 \\
\hline May & 8.32 & 2473 & 56 \\
\hline June & 3.42 & 897 & 23 \\
\hline July & 0.63 & 43 & 2 \\
\hline August & 1.47 & 72 & 2 \\
\hline September & 1.01 & 460 & 16 \\
\hline October & 2.61 & 303 & 9 \\
\hline November & 8.11 & 590 & 14 \\
\hline December & 4.76 & 191 & 8 \\
\hline
\end{tabular}

TAB LE 3 Seasonal variation in accumulated tornado power (ATP), number of tornadoes, and the number of big days by month. The number of tornadoes and the number of big days are based on tornadoes occurring during the period 1994-2017. 


\begin{tabular}{ccccccccc}
\hline UTC Time & 12 & 15 & 18 & 21 & 00 & 03 & 06 & 09 \\
Number of Big Days & 71 & 40 & 56 & 38 & 6 & 1 & 0 & 0 \\
\hline
\end{tabular}

TAB LE 4 Number of big days associated with each UTC time. A big day is associated with the closest 3-hr NARR time prior to the occurrence of the first tornado in the cluster. 


\begin{tabular}{|c|c|c|c|c|c|}
\hline Big Day & $\begin{array}{c}\text { Maximum } \\
\text { CAPE } \\
\left(\mathrm{J} \mathrm{kg}^{-1}\right)\end{array}$ & $\begin{array}{c}\text { Minimum } \\
\mathrm{CIN} \\
\left(\mathrm{J} \mathrm{kg}^{-1}\right)\end{array}$ & $\begin{array}{c}\text { Maximum } \\
\text { Helicity } \\
\left(\mathrm{m}^{2} \mathrm{~s}^{-2}\right)\end{array}$ & $\begin{array}{c}\text { Maximum } \\
\text { Bulk Shear } \\
\left(\mathrm{m} \mathrm{s}^{-1}\right)\end{array}$ & $\begin{array}{c}\text { ATP } \\
(\text { TW })\end{array}$ \\
\hline April 27, 2011 & 2010 & -325 & 829 & 42 & 221 \\
\hline April 24, 2010 & 2630 & -291 & 540 & 39 & 64 \\
\hline April 26, 2011 & 4050 & -141 & 359 & 35 & 46 \\
\hline May 18, 2000 & 2450 & -190 & 321 & 35 & 0.04 \\
\hline April 25, 2003 & 1100 & -206 & 488 & 31 & 0.04 \\
\hline September 26, 2003 & 670 & -22 & 297 & 19 & 0.01 \\
\hline
\end{tabular}

TAB LE 5 Single values for the environmental variables on big days. Big days are separated into top three and bottom three groups based on the value of ATP. 


\begin{tabular}{|r|c|c|c|}
\hline Predictor & $\begin{array}{c}\text { Coefficient } \\
\text { Estimate }\end{array}$ & $\begin{array}{c}\text { Standard } \\
\text { Error }\end{array}$ & $t$ value \\
\hline Intercept & 25.066 & 0.569 & 44.092 \\
Year & 0.050 & 0.016 & 3.061 \\
\hline CAPE & 0.283 & 0.089 & 3.161 \\
\hline Bulk Shear & 0.812 & 0.185 & 4.386 \\
Helicity & 0.109 & 0.063 & 1.720 \\
CIN & -0.080 & 0.101 & -0.797 \\
\hline
\end{tabular}

TAB LE 6 Coefficients from a regression model of ATP onto year, CAPE, bulk shear, CIN, and storm-relative helicity using data from $n=212$ big days in large clusters. The standard error of the estimate and its $t$ value as the ratio of the estimate to the standard error are also given. 